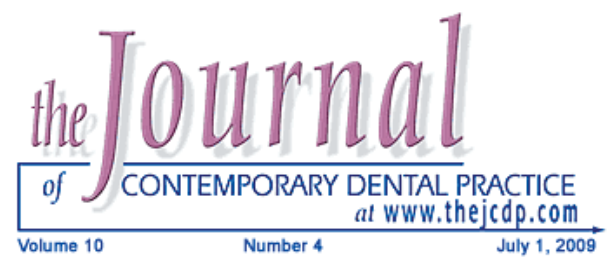

\title{
Clinical Evaluation of Polyamide Polymer Burs for Selective Carious Dentin Removal
}

\section{Attiguppe Prabhakar, MDS; N. K. Kiran, MDS}

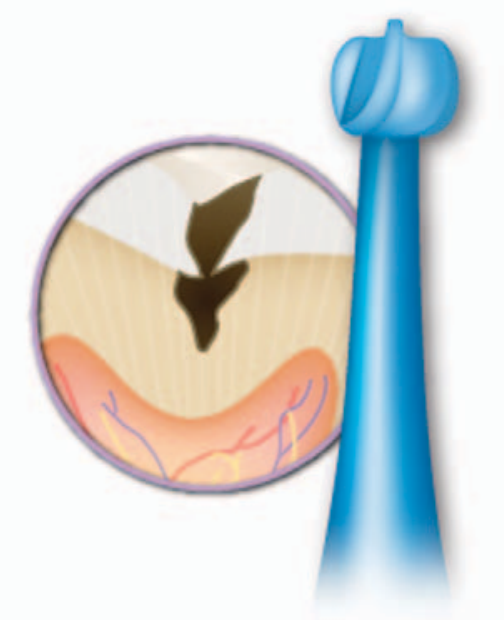

Abstract

Aim: The aim of this study was to evaluate the carious dentin removal efficacy of new rotary polyamide burs capable of selectively removing infected dentin without removing sound dentin.

Methods and Materials: This study included 40 subjects with bilateral occlusal carious lesions on mandibular first permanent molars. The lesions were randomly assigned to receive one restoration after carious dentin removal with a polymer bur and the second after removal of carious dentin with a carbon steel round bur. Both procedures were completed by a single operator in one appointment. The efficacy of caries removal, time taken for caries removal, and patients' perception of the treatment were evaluated. The restorations were evaluated immediately and after six months using intraoral periapical radiographs (IOPA).

Results: The results revealed statistically significant differences between the polymer burs and carbon steel burs with respect to caries removal efficacy $(p<0.001)$ and the time taken for caries removal $(p<0.001)$. No statistically significant results were obtained regarding patients' perception of the treatment and longevity of the restorations.

Conclusion: Carbon steel round burs remove caries lesions more efficiently than polymer burs but they tend to contribute to the over-preparation of the cavity. Polyamide burs were found to be self-limiting and lose their cutting efficiency on reaching affected dentin and do not cut sound dentin. The time required for caries removal using the polymer bur was significantly longer than when using a carbon steel round bur.

(C) Seer Publishing 
Clinical Significance: One of the goals of conservative dentistry is to develop a method for removing caries-infected dentin while preserving caries-unaffected dentin. The use of polymer burs appears to offer a straightforward and efficient means for achieving this goal and conserving healthy tooth structure.

Keywords: Caries removal, caries excavation, carious dentin, outer infected dentin, polymer bur

Citation: Prabhakar A, Kiran NK. Clinical Evaluation of Polyamide Polymer Burs for Selective Carious Dentin Removal. J Contemp Dent Pract 2009 July; (10)4:026-034.

\section{Introduction}

A carious dentinal lesion consists of two distinct layers with different ultramicroscopic and chemical structures. The outer layer is contaminated with bacteria and the organic matrix is substantially degraded and cannot be remineralized requiring its removal and restoration. In contrast, the inner layer can be remineralized because of limited collagen degradation and should be preserved. ${ }^{1}$

This underlying layer of partially demineralized, caries-affected dentin contains dentinal tubules usually filled with Whitlockite caries crystals rendering it highly impermeable to dentinal fluid transudation. ${ }^{2}$ This caries-affected dentin is useful because of its lower permeability compared to healthy dentin and its ability to protect the pulp from any remaining bacteria in the affected dentin. ${ }^{3,4}$ In response to the carious process, the odontoblasts precipitate calcium phosphate to form plugs in the dentin tubules creating an odontoblastic reaction zone. When this phenomenon is combined with the exclusion of

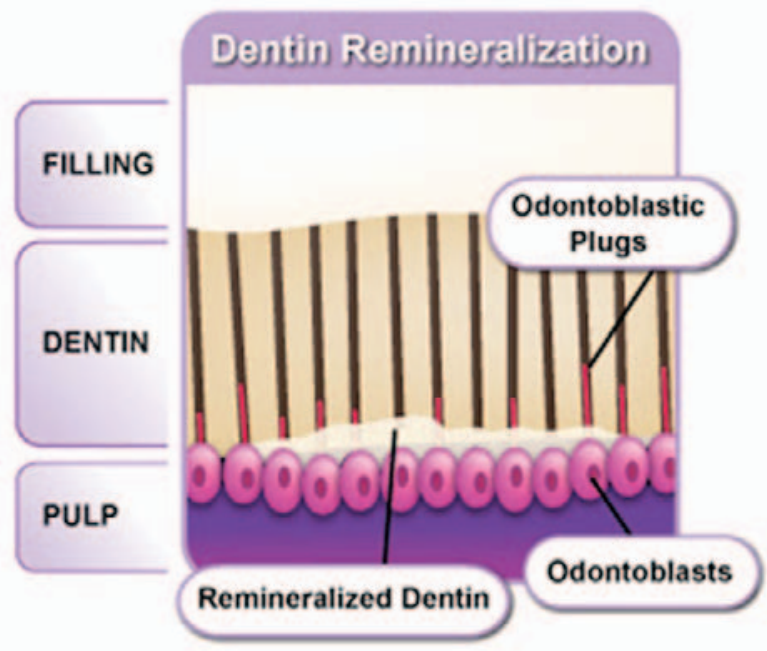

bacteria from external sources of nutrients, caries progress can be arrested for over ten years. ${ }^{5}$

Techniques used for the removal of carious dentin were developed from the time GV Black initially proposed the principle of 'extension for prevention' in the operative treatment of carious lesions in $1893 .{ }^{6}$ However, in recent years, with the advent of adhesive restorative materials and the subsequent developments in minimal cavity design, this widely accepted principle has been challenged and is now considered too destructive an approach for caries removal. ${ }^{7}$

Other techniques used in carious dentin removal include the mechanical rotary or non-rotary instruments, chemo-mechanical techniques, and lasers. The non-rotary, non-invasive techniques include air abrasion, air polishing, ultrasonic, and sono-abrasion. ${ }^{7,8}$

The traditional approach using mechanical rotary instruments is not fundamentally conservative because it often results in cavity preparations extending beyond the infected outer carious dentin layer into the non-infected or lightly infected inner carious dentin or into normal dentin. Carbide dental burs are designed to efficiently remove non-decalcified enamel and dentin but do not facilitate the differentiation between carious and normal dentin during cavity preparation. When this relatively aggressive procedure is combined with the dentist's goal to obtain an excavated surface that feels normal, inadvertent sacrifice of sound dentin is likely to occur. ${ }^{9}$

The Knoop Hardness value of caries-affected dentin is in the range between 10 to 40 kilograms/ square millimeter ${ }^{10}$ while healthy dentin is within the range of 45 to $63 \mathrm{~kg} / \mathrm{mm}^{2}$. ${ }^{11}$ The SmartPrep ${ }^{\circledR}$ 


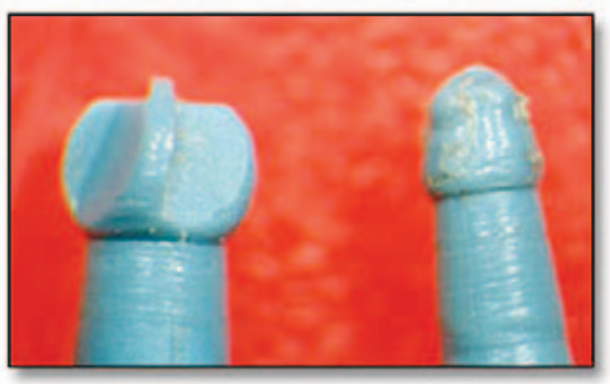

Figure 1. Smart Burs before and after use as observed under stereomicroscope.

(SS White, Lakeland, NJ, USA) single-use, bur-like instrument is made of a medical-grade polymer with hardness less than that of healthy dentin. It is designed for the selective removal of carious dentin through the loss of its cutting efficiency upon reaching the caries-affected dentin. ${ }^{12}$

Polymer burs consist of cutting elements that cut softer dentin efficiently but are unable to cut normal dentin. The cutting blades will deflect and deform upon encountering normal or partially decalcified dentin, thereby enabling the reduction of cutting efficiency and alteration of the operator's tactile sensation (Figure 1).

The bur blades are designed to primarily remove carious dentin by "plowing," during which carious dentin is first locally compressed by the blades then the compressed wall of softened carious dentin is pushed along the more sound dentin surface with rupture eventually occurring at this surface level and the loosened fragments are carried to the surface. ${ }^{9}$ In contrast, removal of normal dentin occurs due to chip formation by orthogonal cutting, during which the blade penetrates the dentin in a wedge like fashion, resulting in plastic deformation and shearing. ${ }^{9}$

The present study was conducted to evaluate the efficacy of selective carious dentin removal using polymer burs with the hypothesis of the study being polymer burs are as efficient as carbon steel round burs in terms of selective dentinal caries removal, time taken for caries removal, and patient perception of the treatment.

\section{Methods and Materials}

Forty children between the ages of six-14 years were selected from different schools using a simple random sampling technique irrespective of sex, race, or socioeconomic status. Approval for the study design was obtained from the local ethical committee and parental consent was obtained prior to treatment.

\section{Inclusion Criteria}

The following represents the inclusion criteria for patient selection:

- Patients should have bilateral occlusal carious lesions on the mandibular first permanent molars with dentinal involvement (extending into the middle or inner third of dentin) as evidenced radiographically and with an opening diameter of at least $2 \mathrm{~mm}$.

- The patients' teeth must display a positive response to sensitivity testing using cold, heat, and mechanical stimulation.

\section{Randomization}

The bilateral mandibular first permanent carious molars in each patient were divided randomly into either the conventional bur group or the polymer bur group.

Every individual taking part in the trial underwent two different types of treatment, one immediately following the other. The treatment type for each tooth and the sequence of treatment were decided using a table of random numbers. ${ }^{13}$

The type of lesion was determined by its opening size and consistency. The largest diameter of the opening size of the lesion was estimated in whole millimeters with a periodontal probe. The teeth were divided into three groups depending on the size of the cavity: $2-3 \mathrm{~mm}, 4-5 \mathrm{~mm}$, and greater than $6 \mathrm{~mm}$. The consistency of the lesion was assessed using a right-angled probe and recorded as:

- Soft - if the probe readily entered the dentin

- Medium - if the probe entered the dentin with some resistance

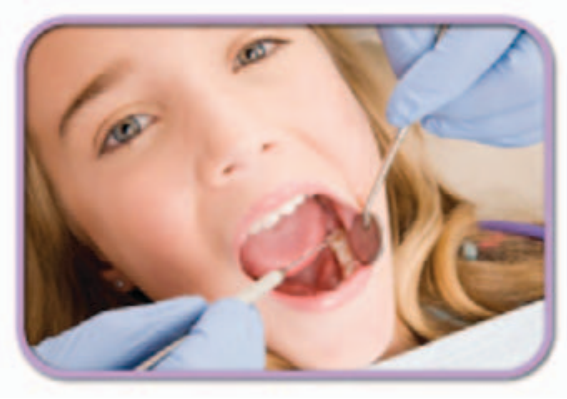



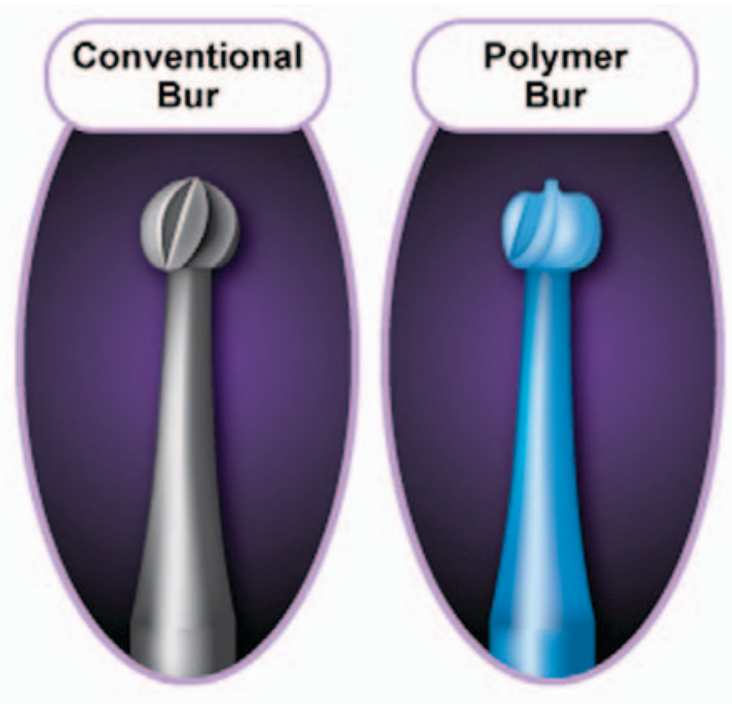

- Hard - if the dentin could not be entered even by firmly pressing the probe

Lesions with dentin exhibiting consistency that involved combinations of any two of these criteria were included in the study. ${ }^{14}$ Local anesthesia was not used in any of the subjects.

\section{Conventional Bur Group}

In cases where there was insufficient access to the carious dentin, an access was prepared with a high-speed drill. The remaining carious dentin was removed by a single operator using carbon steel round burs of ISO sizes 012, 014, and 018 depending on the size of the carious lesion (Dentsply Ash Instruments, Weybridge, Surrey, England). The steel burs were used at a slow speed (approximately 1000-1500 rpm) without a water coolant. ${ }^{15}$ Caries removal was terminated when the operator considered the soft dentin to have been removed from the cavity surface using a straight probe (Kalabhai Dental Pvt. Ltd. Vikhroli, Mumbai, India). The time taken for caries removal, to prepare the cavity, and to remove all the decayed tissue was recorded using a stopwatch. ${ }^{16}$ Time for caries removal was defined as the period from the actual start of the cavity preparation until the dentin excavation was complete. ${ }^{15}$

\section{Polymer Bur Group}

Prior to the onset of the study, the same operator received training in the use of the polymer burs on extracted teeth per the manufacturer's instructions. As was done with the conventional bur group, cases where there was insufficient access to the carious dentin, an access was prepared with a high-speed drill. Soft carious dentin was removed using SmartPrep ${ }^{\circledR}$ polymer bur sizes \#2, 4, and 6, depending on cavity size, running at slow speed (approximately 500 to $800 \mathrm{rpm}$ ) without a water coolant. Cutting was continued until no further chips or flakes of softened dentin were created and the bur ceased to progress into the sound dentin. ${ }^{9}$ Additional polymer burs were used in the event the first bur became dull on inadvertent contact with the sound dentin and/or adjacent enamel. ${ }^{17}$

The time taken for caries removal was noted using a stopwatch. This included the period from the actual start of the cavity preparation, until the dentin excavation was complete. ${ }^{15}$

In order to eliminate interpersonal variation, two blinded co-investigators participated in this study to assess the completeness of the caries removal and evaluated the restorations radiographically using the described clinical criterion. The blinded investigators had previously received training on the evaluation criteria using visual and clinical aids for the assessment of caries removal. Without knowledge of the assignment of the teeth to treatment groups the co-investigators examined each cavity to determine whether each cavity was caries free. $^{18}$

\section{The Evaluation Criteria}

The efficacy of caries removal was evaluated using visual and tactile criteria. The visual criterion was the absence of any dentin discoloration and the tactile criterion was the smooth passage of an explorer over the surface of the affected area of the dentin without a catch or a 'tug back' sensation. ${ }^{16}$ The efficacy of caries removal was verified using Caries Detector (Kuraray Medical Inc, Tokyo, Japan) caries detector dye for ten seconds followed by rinsing with water for ten seconds. ${ }^{19}$ Efficacy was graded as complete, partial, and incomplete and numerically scored as $0,1,2,3,4,5$ using the criteria proposed by Munshi AK, et al. ${ }^{16}$ (Table 1).

Patient evaluation of the procedure was carried out immediately after the treatment. Without further explanation patients were simply asked whether they experienced any pain or 
Table 1. Scoring criteria for the assessment of the efficacy of caries removal. ${ }^{16}$

\begin{tabular}{|c|l|}
\hline Score & \multicolumn{1}{c|}{ Definition } \\
\hline 0 & Caries completely removed. \\
\hline 1 & Caries present in the base of the cavity preparation. \\
\hline 2 & Caries present in the base and/or in one wall of the cavity preparation. \\
\hline 3 & Caries present in the base and/or two walls of the cavity preparation. \\
\hline 4 & Caries present in the base and/or more than two walls of the cavity preparation. \\
\hline 5 & Caries present in the base, walls, and margins of the cavity preparation. \\
\hline
\end{tabular}

Table 2. Criteria for evaluation of the longevity of restorations. ${ }^{16}$

\begin{tabular}{|c|l|}
\hline Score & \multicolumn{1}{|c|}{ Criteria } \\
\hline 0 & Restoration present; no gap between the cavity walls and restoration. \\
\hline 1 & Gap and/or restoration partially present; no signs of caries. \\
\hline 2 & Gap and/or restoration partially present. Signs of caries observed. \\
\hline 3 & Restoration not present; no signs of caries. \\
\hline 5 & Restoration not present; signs of caries observed. \\
\hline
\end{tabular}

discomfort. ${ }^{20}$ The response options were: no discomfort, mild discomfort, or severe discomfort.

In both types of preparations special attention was paid to removing all the poorly supported enamel. When necessary, a radiopaque calcium hydroxide base (Dycal ${ }^{\circledR}$, Dentsply, LD Caulk, USA) was applied to the deepest areas of the cavity in both treatment groups. The cavities were then restored with GC Fuji IX GP cement (GC Corporation, Tokyo, Japan), which was mixed according to the manufacturer's instructions. The restorations were checked for high points using articulating paper, and the restoration surfaces were protected with a coat of GC Varnish ${ }^{\circledast}$ (GC Corporation, Tokyo, Japan).

Following placement of the restoration, an intraoral periapical (IOPA) radiograph was taken using a standardized paralleling cone technique with No. 2 size Kodak, E-speed film (Carestream Health, Inc. Rochester, NY, USA) and processed using automatic processing to facilitate immediate evaluation. After a period of six months, the longevity of the restorations and the presence of secondary caries at the restoration-dentin interface were evaluated again radiographically based on the criteria used by Munshi AK, et al. ${ }^{16}$ (Table 2).

The comparison of caries removal scores between procedures performed using the polymer and the carbon steel round bur were assessed using the Chi square test. The comparison of the time taken for caries removal using the polymer bur and the carbon steel round bur was assessed using the Unpaired t-test. The differences between the radiographic evaluation scores obtained immediately after the restoration placement 
and during the six-month follow-up, if any, were assessed using the Chi-square test.

\section{Results}

\section{Results of the Caries Excavation}

In the polymer bur group, $65 \%$ of the lesions showed complete removal of caries while $35 \%$ showed partial removal of caries. In the carbon steel bur group, all the lesions showed complete removal of carious dentin. The differences between the scores were statistically significant $\left(\chi^{2}=16.9, p<0.001\right)($ Table 3$)$.

Among the soft carious lesions treated using the polymer bur, $76 \%$ showed complete removal of soft carious dentin while $24 \%$ showed partial removal of caries. Among the soft lesions treated using the carbon steel bur, $46.6 \%$ showed complete removal of carious dentin and $53.4 \%$ showed partial removal of caries. When comparing the caries removal efficacy of the polymer and carbon steel burs in treating soft lesions, there was a statistically significant difference $(\mathrm{P}=0.003)$ (Table 4).

\section{Time Consumption for Excavation}

Tables 5 and 6 show the comparison of the mean time consumption for caries removal. The differences between the scores were statistically significant. $(P<0.001)$

\section{Patient Perception of the Treatment} Table 7 shows the comparison of patient comfort between the polymer bur group and the carbon steel bur group upon caries removal. The differences were not statistically significant.

Table 3. Comparison of the caries removal scores using polymer bur and carbon steel round bur.

\begin{tabular}{|c|c|c|c|c|c|c|c|c|}
\hline \multirow{2}{*}{ Bur } & \multirow{2}{*}{$\begin{array}{l}\text { No. of } \\
\text { lesions }\end{array}$} & \multicolumn{6}{|c|}{$\begin{array}{l}\text { No. of lesions represented by each score caries } \\
\text { removal scores }\end{array}$} & \multirow{2}{*}{ Mean \pm SD } \\
\hline & & 0 & 1 & 2 & 3 & 4 & 5 & \\
\hline Polymer & 40 & $\begin{array}{c}26 \\
(65 \%)\end{array}$ & $\begin{array}{c}8 \\
(20 \%)\end{array}$ & $\begin{array}{c}6 \\
(15 \%)\end{array}$ & - & - & - & $0.5 \pm 0.8$ \\
\hline Carbon steel round & 40 & $\begin{array}{c}40 \\
(100 \%)\end{array}$ & - & - & - & - & - & $0.0 \pm 0$ \\
\hline$=16.9 p<0.001, \mathrm{HS}$ & & & & & & & & \\
\hline
\end{tabular}

Table 4. Comparison of the caries removal scores for the soft and medium lesions using polymer bur and carbon steel round bur.

\begin{tabular}{|c|c|c|c|c|c|c|c|c|c|c|}
\hline \multirow{2}{*}{$\begin{array}{l}\text { Consistency } \\
\text { of Carious } \\
\text { Lesion }\end{array}$} & \multirow{2}{*}{ Bur Type } & \multirow{2}{*}{$\begin{array}{l}\text { No. of } \\
\text { Lesions }\end{array}$} & \multicolumn{6}{|c|}{$\begin{array}{l}\text { No. of lesions representing caries } \\
\text { removal scores }\end{array}$} & \multirow{2}{*}{ Mean \pm SD } & \multirow{2}{*}{ Significance } \\
\hline & & & 0 & 1 & 2 & 3 & 4 & 5 & & \\
\hline \multirow{2}{*}{ Soft } & Polymer & 25 & $\begin{array}{c}19 \\
(76 \%)\end{array}$ & $\begin{array}{c}4 \\
(16 \%)\end{array}$ & $\begin{array}{c}2 \\
(8 \%)\end{array}$ & - & - & - & $0.3 \pm 0.6$ & \multirow{2}{*}{$\begin{array}{c}P=0.003 \\
S\end{array}$} \\
\hline & Steel & 30 & $\begin{array}{c}7 \\
(46.6 \%)\end{array}$ & $\begin{array}{c}4 \\
(26.7 \%)\end{array}$ & $\begin{array}{c}4 \\
(26.7 \%)\end{array}$ & - & - & - & 0.0 & \\
\hline \multirow{2}{*}{ Medium } & Polymer & 15 & $\begin{array}{c}30 \\
(100 \%)\end{array}$ & - & - & - & - & - & $0.8 \pm 0.9$ & \multirow{2}{*}{$\begin{array}{c}P=0.005 \\
S\end{array}$} \\
\hline & Steel & 10 & $\begin{array}{c}10 \\
(100 \%)\end{array}$ & - & - & - & - & - & 0.0 & \\
\hline
\end{tabular}


Table 5. Comparison of time (minutes) taken for caries removal using polymer bur and carbon steel round bur.

\begin{tabular}{|c|c|c|c|c|c|}
\hline \multirow{2}{*}{ Bur } & \multirow{2}{*}{$\begin{array}{l}\text { No. of } \\
\text { Lesions }\end{array}$} & \multicolumn{3}{|c|}{ Time Taken (Min) } & \multirow{2}{*}{ Significance } \\
\hline & & Range & Mean & SD & \\
\hline Polymer & 40 & $2.2-5.2$ & 3.60 & 0.8 & \multirow{2}{*}{$\begin{array}{c}T=6.26 \\
P<0.001, H S\end{array}$} \\
\hline Carbon Steel & 40 & $1.2-4.2$ & 2.55 & 0.7 & \\
\hline
\end{tabular}

Table 6. Time taken for caries removal of the lesions with varying occlusal opening diameter using polymer bur and carbon steel round bur.

\begin{tabular}{|c|c|c|}
\hline \multirow{2}{*}{$\begin{array}{c}\text { Opening Diameter } \\
(\mathrm{mm})\end{array}$} & \multicolumn{2}{|c|}{ Time Taken (minutes) } \\
\cline { 2 - 3 } & Polymer Bur & Carbon Steel Round Bur \\
\hline $2-3$ & $3.19 \pm 0.4(n=19)$ & $2.20 \pm 0.52(n=26)$ \\
\hline $4-6$ & $3.97 \pm 0.75(n=21)$ & $3.21 \pm 0.65(n=14)$ \\
\hline$n=$ number of lesions & & \\
\hline
\end{tabular}

Table 7. Comparison of patient comfort on caries removal using polymer bur and carbon steel round bur.

\begin{tabular}{|l|c|c|}
\hline \multicolumn{1}{|c|}{ Bur } & No Discomfort & Mild Discomfort \\
\hline Polymer $(n=40)$ & $12(30 \%)$ & $28(70 \%)$ \\
\hline Steel $(n=40)$ & $19(47.5 \%)$ & $21(52.5 \%)$ \\
\hline
\end{tabular}

Table 8. Comparative radiographic evaluation scores of the restorations immediately and after six months follow-up.

\begin{tabular}{|c|c|c|c|c|c|c|c|c|c|c|c|c|}
\hline \multirow{2}{*}{ Bur } & \multirow{2}{*}{ No. of Lesions } & \multicolumn{5}{|c|}{ Immediate Scores } & \multicolumn{5}{|c|}{ After 6 month follow-up } & \multirow{2}{*}{$\begin{array}{c}\text { Immediate v/s } \\
6 \text { months }\end{array}$} \\
\hline & & 0 & 1 & 2 & 3 & 4 & 0 & 1 & 2 & 3 & 4 & \\
\hline Polymer & 40 & $\begin{array}{c}27 \\
(67.5 \%)\end{array}$ & $\begin{array}{c}13 \\
(32.5 \%)\end{array}$ & $\cdot$ & $\cdot$ & $\cdot$ & $\begin{array}{c}27 \\
(67.5 \%)\end{array}$ & $\begin{array}{c}13 \\
(32.5 \%)\end{array}$ & - & $\cdot$ & - & No difference \\
\hline $\begin{array}{l}\text { Carbon } \\
\text { Steel } \\
\text { Round }\end{array}$ & 40 & $\begin{array}{c}28 \\
(70 \%)\end{array}$ & $\begin{array}{c}12 \\
(30 \%)\end{array}$ & - & - & - & $\begin{array}{c}28 \\
(70 \%)\end{array}$ & $\begin{array}{c}12 \\
(30 \%)\end{array}$ & - & - & - & No difference \\
\hline \multicolumn{2}{|c|}{ Polymer vs. Carbon Steel } & \multicolumn{5}{|c|}{$P=0.81, N S$} & \multicolumn{5}{|c|}{$P=0.81 \mathrm{NS}$} & \\
\hline
\end{tabular}


Immediate and Six-month Radiographic Evaluation of the Restorations

On immediate radiographic evaluation, $67.5 \%$ of the carious lesions treated using the polymer bur showed the absence of gaps between the restoration-dentin and $32.5 \%$ showed partial presence of gaps. After a six month radiographic evaluation, there were no changes in the status of the restorations. None of the treated lesions showed the presence of secondary caries.

On immediate radiographic evaluation, $70 \%$ of the carious lesions treated using the carbon steel round bur showed the absence of gaps between the wall and the base of the cavity while $30 \%$ showed the partial presence of gaps at the restorationdentin interface. After a six month radiographic evaluation, there were no changes in the status of the restoration. None of the treated lesions showed the presence of secondary caries (Table 8).

\section{Discussion}

The removal of infected dentin without affecting dentin capable of remineralization has been the ultimate goal of conservative restorative dentistry. However, a rapid but controlled method of selective carious dentin removal has remained elusive. A rotary instrument capable of being used at low speed with its cutting ability limited to the infected layer and the initial layer of affected dentin has conceptual appeal. ${ }^{12}$

As shown in many studies, certain clinical parameters such as dentin discoloration cannot be reliably associated with caries activity and infection. ${ }^{21}$ Even though dentin hardness and moisture correlate better with microbiological activity, these are still subjective parameters and many lesions can be incorrectly classified or remain unclassified. ${ }^{22}$

In the present study the visual and tactile criterion' was adopted because it is the most widely used clinical criterion to evaluate complete caries removal. The difficulty in accurately and reliably detecting infected carious dentin by tactile and visual examination alone is well-established. Fortunately, removal of carious dentin can be guided by staining it with caries detection dyes ${ }^{23}$ so the cavity preparations in this experiment were verified for completeness of caries removal using a caries detector dye.

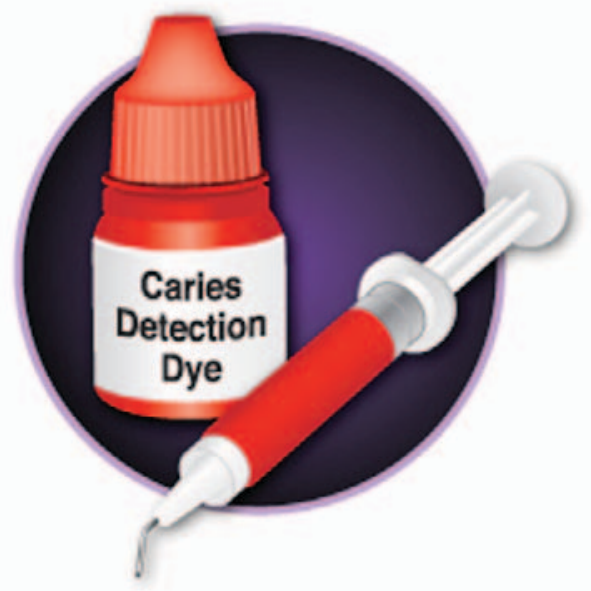

Although such dyes have been claimed to better discriminate between infected dentin and partially demineralized dentin compared to clinical evaluation alone, they appear to stain the demineralized organic matrix rather than the bacteria. ${ }^{19} \mathrm{McComb}{ }^{24}$ criticized the lack of specificity of these dyes and recommended other clinical evaluation methods such as the visual and tactile examination and radiographs as viable alternatives. The present study took place in-vivo, and the selected teeth could not be sacrificed and subjected to more effective methods ${ }^{10}$ like confocal laser scanning microscopy to ascertain completeness of caries removal. As a result, a combination of all aforementioned evaluation methods were used in the study.

In the present study complete caries removal using the carbon steel round bur was achieved in all the lesions examined, whereas it was accomplished in only $65 \%$ of the lesions treated using the polymer bur. None of the lesions treated by the carbon steel round bur stained with caries detector dye, indicating the possibility of excessive removal of sound dentin. These results were in total agreement with the results of previous studies by Banerjee et al. ${ }^{8}$ and Celiberti, et al. ${ }^{22}$

Conventional burs normally present a negative rake angle, which means the blade is ahead of the site perpendicular to the surface being cut. In order to keep the blade in contact with this surface, increased downward pressure is needed. This can lead to a less controlled movement of the instrument through the surface, resulting in excessive dentin removal. ${ }^{22}$ 
The lesions treated by the polymer bur stained pink or light pink. A growing body of research suggests leaving this amount of stained dentin (resulting in pink or light pink staining) signals the avoidance of excessive dentin removal. ${ }^{19,21,25}$ Several investigations have shown a low number of residual microorganisms often remain in clinically sound, hard dentin despite a significant reduction in the bacterial count; however, this low number of bacteria is considered to be clinically acceptable by several investigators. ${ }^{26}$

The results of the present study suggest the polymer bur is more efficient in treating soft carious lesions than more firm lesions. A finding previously reported by Celiberti et al. ${ }^{21}$ showed remaining dentin, after complete removal of soft caries, to appear hard and burnished. However, based on the clinical findings of the Celiberti et al. ${ }^{21}$ study alone it was not possible to determine if the difficulty of using the polymer bur to excavate hard, dark, and discolored dentin is considered as a positive or a negative aspect of the technique. Further tests employing microbiological validation need to be done to assess the outcome of different excavation methods in the treatment of active and arrested caries lesions.

The time required for carious dentin removal using the polymer bur was longer than when using the carbon steel round bur. These results are in accord with those obtained in a study by Allen et al. ${ }^{12}$ The excess time required when using the polymer bur might be attributed to the following factors:

- The very low rotational speed of the bur (approximately $800 \mathrm{rpm}$ )

- The path taken by the instrument while removing the infected dentin (working from the center and top of the lesion progressively out and then down, removing layer by layer throughout the lesion)

- The polymer bur is less hard compared to healthy dentin, rendering the instrument to be self-limiting

However, it is interesting to note the mean time required for complete caries removal using the polymer bur was shorter than the time required for other techniques like the Atraumatic Restorative Technique or chemo-mechanical procedures. ${ }^{27}$ Furthermore, the additional time needed to selectively remove softened dentin using a polymer bur was marginal and can be considered a minor drawback compared to its advantages. Only one previous study has reported a longer preparation period with a steel bur compared to a polymer bur. $^{28}$

Rotary instruments have several drawbacks including bone-conducted vibration, high-pitched noise of the air turbine, sensitivity of the vital dentin, and the development of high temperature at the cutting surface which leads to thermal stimulation. ${ }^{8}$ In the present study patients who were treated using the polymer bur experienced more discomfort than those treated using the carbon steel round bur. These results are in accord with those obtained in a study by Allen, et al. ${ }^{12}$ who also compared the discomfort associated with polymer bur instrumentation without local anesthesia and carbide bur instrumentation with local anesthesia. However, in the present study no local anesthesia was used. The discomfort experienced by the polymer bur group may be attributed to the low hardness of polymer bur compared to sound dentin and the vibration, heat, and pressure generated during the excavation procedure.

The restorations were evaluated using radiographs immediately after the treatment and again after a period of six months. The six month radiographic examination showed no changes in the status of the restorations and none of the treated lesions showed the presence of secondary caries.

The caries process or the reactivation of residual caries after the operative management of the carious lesion is influenced by the following:

1. Restriction of the nutrient supply by isolating the caries process from the oral cavity

2. Operative treatment, i.e., excavating the carious dentin

3. Use of a cariostatic filling material

In the present study all the three therapies controlling progress of the carious lesion were included. Secluding the caries process from the oral environment definitely led to a reduction in the number of microorganisms. Cariostatic properties of some filling materials can supposedly ensure reduction in the microorganism number. The cariostatic effect of the glass 
ionomer cement used in the present study is well known. ${ }^{26}$ Additionally, its physicochemical bonding to dentin could have inhibited bacterial percolation through the tooth/restoration interface. These properties enable a satisfactory margin seal, making it difficult for the remaining microorganisms to survive and creating conditions suitable for a physiological remineralization process. ${ }^{29}$ Hence, it appears that a combination of the three strategies mentioned above could have played a key role in preventing the progress of carious lesions.

The results of the present study suggest using a steel bur is the fastest method of removing carious dentin for all cavity sizes and consistencies of lesions. However, this method is also the least conservative and is the most likely to be influenced by operator manipulation.

\section{Conclusion}

The following conclusions were drawn from this study:

1. Carbon steel round burs remove caries lesions more efficiently than polymer burs. However, it appears the usage of carbon steel round burs tend to over-prepare the cavity. The polymer bur was self-limiting and the cutting efficiency decreased on reaching the affected dentin and did not cut sound dentin. Upon radiographic evaluation of the restorations, none of the treated lesions showed the presence of secondary caries.

2. The time taken for caries removal using the polymer bur was significantly longer than that when using the carbon steel round bur. No statistically significant differences were observed with respect to patient perception of the treatment by the two types of burs.

With modifications of the composition/hardness of the polymer bur to ensure complete removal of infected tissue, this novel self-limiting concept of caries removal has the potential to improve caries removal techniques. A new, re-designed version of the polymer bur is already on the market and further studies are warranted.

\section{Clinical Significance}

One of the goals of conservative dentistry is to develop a method for removing caries-infected dentin while preserving caries-unaffected dentin. The use of polymer burs appears to offer a straightforward and efficient means for achieving this goal and conserving healthy tooth structure. 


\section{References}

1. Fusayama T. Two layers of carious dentin: diagnosis and treatment. Oper Dent 1979; 4:63-70.

2. Lee KW, Son HH, Yoshiyama M, Carvalho RM, Pashley DH. Sealing properties of a self-etching primer system to normal caries-affected and caries-infected dentin. Am J Dent 2003; 16(Spec No A):68A-72A.

3. Pashley EL, Talman R, Horner JA, Pashley DH. Permeability of normal versus carious dentin. Endo Dent Traumatol 1991; 7(5):207-211.

4. Pashley DH, Pashley EL, Carvalho RM, Tay FR. The effects of dentin permeability on restorative dentistry. Dent Clin North Am 2002; 46(2):211-245, v-vi.

5. Mertz-Fairhurst EJ, Curtis JW Jr, Ergle JW, Ruggeberg FA, Adair SM. Ultraconservative and cariostatic sealed restorations: results at year 10. J Am Dent Assoc 1998; 129(1):55-66.

6. Black GV (1892). Extension for prevention. IL State Dent Soc Trans (From: Boston DW. New device for selective dentin caries removal. Quintessence Int 2003; 34:678-685.

7. Elderton RJ. New approach to cavity design with special reference to the class II lesion. Br Dent J 1984; 157:421-427.

8. Banerjee A, Watson TF, Kidd EAM. Dentin caries excavation: a review of current clinical techniques. Br Dent J 2000; 188:476-482.

9. Boston DW. New device for selective dentin caries removal. Quintessence Int 2003; 34:678-685.

10. Yoshiama M, Tay FR, Doi J. Bonding of self etch and total etch adhesives to carious dentin. J Dent Res 2002; 81:556-560.

11. Wei SH, Kaqueller JC, Massler M. Remineralization of carious dentin. J Dent Res 1968; 47:381-391.

12. Allen KL, Salgado TL, Janal MN, Thompson VP. Removing carious dentin using a polymer instrument without anesthesia versus a carbide bur with anesthesia. J Am Dent Assoc 2005; 136:643-650.

13. Pocock SJ. Clinical Trials. New York, Wiley \& Sons, 1993, p 129.

14. Fure S, Lingstorm $P$, Birkhed D. Evaluation of Carisolv for the Chemo-Mechanical Removal of Primary Root Caries in vivo. Caries Res 2000; 34:275-280.

15. Rahimtoola S, Maher R. Pain related to treatment of caries lesion. J Dent Child 2000; 67:123-127.

16. Munshi AK, Hegde AM, Shetty PK. Clinical evaluation of carisolv in the chemico-mechanical removal of carious dentin. J Clin Pediatr Dent 2001; 26(1):49-54.

17. Silva NRFA, Carvalho RM, Pegoraro LF, Tay FR, Thompson VP. Evaluation of a self limiting concept in dentinal caries removal. J Dent Res 2006; 85(3):282-286.

18. Ericson D, Zimmerman M, Raber H, Gotric B, Bornstein R. Clinical Evaluation of Efficacy and Safety of a New Method for Chemo-Mechanical Removal of Caries. Caries Res 1999; 33:171-177.

19. Yip HK, Stevenson AG, Beeley JA. The specificity of caries detector dyes in cavity preparation. Br Dent J 1994; 176:417-420.

20. Van Amerongen WE, Rahimtoola S. Is ART really atruamatic. Community Dent Oral Epidemiol 1999; 27:431-435.

21. Kidd EA, Joyston-Bechal S, Beighton D. The use of caries detector dye during cavity preparation: a microbiological assessment. Br Dent J 1993; 174:245-248.

22. Caliberti $P$, Francescut $P$, Lussi $A$. Performance of four dentine excavation methods in deciduous teeth. Caries Res 2006; 40:117-123.

23. Thylstrup A, Fejerskov O. Textbook of Clinical Cariology. 2nd ed. Copenhagan: Munksgard; 1994. p.111-157.

24. McComb D. Caries detector dyes - How accurate and useful are they? J Can Dent Assoc 2000; 66:195-198.

25. Banerjee A, Kidd EAM, Watson TF. In vitro validation of carious dentin removed using different excavation criteria. Am J Dent 2003; 16:228-230.

26. Weerheijm KL, Groen HJ. The residual caries dilemma. Community Dent Oral Epidemiol 1999; 27:436-441.

27. Maragakis GM, Hahn P, Hellwig E. Chemo mechanical caries removal: a comprehensive review of the literature. International Dental Journal 2001; 51:291-299. 
28. Dammaschke T, Rodenberg TN, Schäfer E, Ott KHR. Efficiency of the Polymer Bur Smart Prep Compared with Conventional Tungsten Carbide Bud Bur in Dentin Caries Excavation. Oper Dent. 2006; 31(2):256-260.

29. Massara MLA, Alves JB, Brandao PRG. Atruamatic Restorative Treatment: Clinical, Ultrastructural and Chemical Analysis. Caries Res 2002; 36:430-436.

\section{About the Authors}

\section{Attiguppe Prabhakar, MDS}

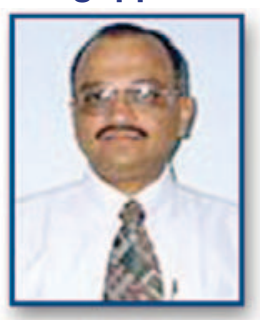

Dr. Prabhakar is a Professor and Head of the Department of Pedodontics and Preventive Dentistry of the Bapuji Dental College and Hospital in Davangere, Karnataka, India.

e-mail: attiguppeaprabhakar@yahoo.com

\section{N. K. Kiran, MDS}

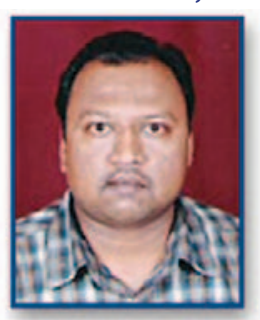

Dr. Kiran is a post graduate student in the Department of Pedodontics and Preventive Dentistry of the Bapuji Dental College and Hospital in Davangere, Karnataka, India.

e-mail: drkirannk@gmail.com 